\title{
Efeito da Amonização com Uréia sobre os Parâmetros de Qualidade do Feno do Capim-Annoni 2 (Eragrostis plana Nees) ${ }^{1}$
}

\section{Hero Alfaya ${ }^{2}$, Luciane Nunes Pereira Suñé ${ }^{3}$, Cleia Maria Gisler Siqueira ${ }^{3}$, Derli João Siqueira da Silva ${ }^{3}$, João Baptista da Silva ${ }^{4}$, Everton Madeira Pederzolli ${ }^{5}$, Werner Erwin Lüeder $^{2}$}

RESUMO - Este estudo visou avaliar o efeito da amonização do feno de capim-Annoni 2 (Eragrostis plana Nees) com 4\% de uréia, em base de matéria seca, sobre os teores de proteína bruta (PB), fibra detergente neutro (FDN), fibra detergente ácido (FDA), hemicelulose (HEM), celulose (CEL) e lignina (LIG) e o coeficiente da digestibilidade in vitro da matéria orgânica (DIVMO), em cinco épocas de corte (30,60, 90, 120, 150 dias). O delineamento experimental foi o de blocos completos casualisados, em número de quatro, num arranjo fatorial (2x5) com dois fatores: tratamento dos fenos (2) e épocas de corte (5). A comparação entre os dois grupos de fenos (amonizados ou não) demonstrou que a amonização propiciou aumento altamente significativo dos teores de PB. Por outro lado, a fração de FDA decresceu significantemente, juntamente com os teores de CEL, em função do tratamento com uréia. Não foram detectadas diferenças entre os tratamentos, relativamente aos teores de FDN, HEM, LIG e ao coeficiente da DIVMO. Inferiu-se que: 1. a amonização do feno de capimAnnoni 2 não afetou os teores de FDN , HEM, LIG e os coeficientes da DIVMO; 2. tratamento do feno de capim-Annoni 2 com uréia propiciou aumento nos teores de PB e decréscimo nos teores de FDA e CEL; 3. o capim-Annoni 2 pode ser fenado até os 90 dias de crescimento, sem que ocorram modificações expressivas dos parâmetros de qualidade, desde que o feno seja amonizado.

Palavras-chave: celulose, fibra detergente ácido, fibra detergente neutro, hemicelulose, lignina, proteína bruta

\section{Effect of Urea-Ammonia Treatment on the Quality Parameters of Annonigrass 2 (Eragrostis plana Nees) Hay}

\begin{abstract}
This study aimed to evaluate the ammoniation effect on the crude protein (CP), neutral detergent fiber (NDF), acid detergent fiber (ADF), hemicellulose (HEM), cellulose (CEL) and lignin (LIG) levels and the in vitro organic matter digestibility (IVOMD) coefficient of urea-ammonia treated (4\%; dry matter basis) Annonigrass 2 (Eragrostis plana Nees) hay, at five cutting ages (30, 60, 90, 120, 150 days). A randomized complete block design was used, with four replicates in a factorial arrangement (2x5), with two factors: hay treatments (2) and cutting ages (5). The comparison among hay groups (ammoniated or not) showed a highly significant increase on the CP contents of ammoniated hay. On the other hand, FDA and CEL fraction significantly decreased as a function of urea-ammonia treatment. No differences were found for NDF, HEM, LIG contents and the IVOMD coefficients among hay groups. It was concluded that: 1. ammoniation does not affect NDF, HEM, LIG levels and IVOMD coefficients; 2. urea-ammonia treatment of Annonigrass 2 hay promotes an increase on the CP contents and a decrease on the ADF and CEL contents of this grass; 3 . Annonigrass 2 hay is feasible up to 90 days of growth without prejudice to the quality parameters, since urea-ammonia is treated.
\end{abstract}

Key Words: acid detergent fiber, cellulose, crude protein, hemicellulose, lignin, neutral detergent fiber

\section{Introdução}

Desde o aparecimento do capim-Annoni 2 (Eragrostis plana Nees) no Rio Grande do Sul nos anos 50, a disseminação dessa gramínea, originária do sudoeste da África, em áreas de campo natural, tomou proporções enormes, estando hoje disseminada por todas as regiões do estado (Reis \& Coelho, 1999).

Acompanhando essa trajetória, nos anos 70, iniciaram-se investigações acerca da sua qualidade nutricional, foram feitas avaliações agronômicas e de utilização dessa gramínea como forrageira para animais em pastejo. Com resultados pouco promissores e a conseqüente proibição da comercialização de sementes pelos órgãos oficiais em 1979, em função de ser considerada uma planta invasora, a partir dos anos 80 , os esforços concentraram-se em estudos relativos à erradicação e/ou controle do capim-Annoni 2.

Atualmente, os conhecimentos adquiridos sobre o capim-Annoni 2 espelham o seu histórico, ou seja,

\footnotetext{
${ }_{1}^{1}$ Parte da dissertação de mestrado do segundo autor, apresentada ao curso de Pós-Gradução em Zootecnia da UFPel

2 Professor, Dep. de Zootecnia, FAEM-UFPel, CEP 96010-970, Pelotas-RS. E.mail: alfaya @ ufpel.tche.br

3 Professor, Universidade da Região da Campanha-URCAMP, Bagé-RS.

4 Professor, Departamento de Matemática e Estatística, UFPel, Pelotas-RS.

5 Aluno do curso de Bacharelado e Licenciatura em Química, UFPel, Pelotas-RS.
} 
enquanto a literatura sobre os métodos de controle é relativamente extensa, aquela sobre a sua qualidade é escassa e, de certa forma, controversa, uma vez que os únicos estudos mais abrangentes sobre o valor nutritivo do capim-Annoni 2 (Nascimento, 1976; Nascimento \& Hall, 1978; Hall \& Nascimento, 1978) apresentam resultados que, às vezes, superam qualitativamente aqueles obtidos com a vegetação de campo natural. Além disso, até o presente momento, existe uma lacuna de informações sobre essa planta, no que se refere à fração fibrosa e seus componentes.

Todavia, é consenso geral que essa gramínea deve ser erradicada e/ou controlada, em virtude de que não apresenta vantagens em relação à qualidade nutricional da vegetação de campo natural e, principalmente, pelo seu caráter de invasora.

Entretanto, a erradicação e/ou controle do capimAnnoni 2 é muito difícil após o seu estabelecimento (Reis, 1993), uma vez que o principal vetor de infestação é o banco de sementes existente no solo, em virtude da capacidade dessa planta de produzir sementes, bem como da viabilidade de germinação (97\%) das mesmas (Coelho, 1983).

No intuito de esgotar o banco de sementes do solo, Coelho \& Reis (1990) propuseram um método bastante eficaz, denominado "controle integrado", a ser desenvolvido em áreas agricultáveis. Este método alia o combate químico (herbicidas, graminicidas) com a introdução de culturas e/ou forrageiras anuais. Contudo, conforme Reis \& Coelho (1999), o uso destas tecnologias, se bem aplicadas, somente é eficiente para o controle imediato e a convivência com a invasora, pois com o reaparecimento da espécie, o "controle integrado" deve ser utilizado novamente.

Levando em consideração os avanços nas investigações para a erradicação e analisando a problemática do capim-Annoni 2 como planta invasora, Coelho (1993) indica que o problema ainda não foi solucionado em virtude de: 1 . ainda não existirem soluções para áreas comuns (estradas, locais de remates de animais etc.); 2. os produtores não utilizarem as tecnologias geradas, relativas ao combate da planta; 3 áreas de difícil acesso, relevo acidentado, afloramento de rocha, dificultarem o combate da planta.

Para áreas já infestadas, em razão dos dois últimos problemas, Alfaya et al. (2000) propõem o corte do capim-Annoni 2 em estádios de desenvolvimento anteriores à sementação, como alternativa adjuvante para a diminuição paulatina do banco de sementes do solo e a conservação pós-corte na forma de feno. Entretanto, devido ao fato de que, em épocas mais avançadas de crescimento, o valor nutritivo dessa gramínea é baixo (Hall \& Nascimento, 1978; Nascimento \& Hall, 1978), Alfaya et al. (2000) propõem ainda a amonização com uréia agrícola como técnica alternativa, econômica e de fácil aplicação, para melhorar a qualidade do feno.

Nesse sentido, o presente estudo teve por objetivo avaliar o efeito da amonização com uréia sobre os parâmetros de qualidade do feno de capim-Annoni 2, em cinco épocas de corte, e determinar a melhor época para a fenação e amonização dessa gramínea.

\section{Material e Métodos}

O experimento foi realizado no município de BagéRS, região agroecológica da Campanha, sobre solo Podzólico Bruno-acinzentado. O clima da região é o temperado úmido. A cobertura vegetal da área era composta únicamente pelo capim-Annoni 2 , que se estabeleceu no local há mais de 25 anos.

$\mathrm{O}$ delineamento experimental foi o de blocos completos casualizados, com quatro repetições, em arranjo fatorial $(2 \times 5)$ com dois fatores: tratamento dos fenos (2) e épocas de corte (5). As parcelas, sorteadas ao acaso dentro dos quatro blocos, representaram as cinco épocas de corte $(30,60,90,120$, 150 dias).

No início da primavera (30 de setembro), a área recebeu um corte de uniformização e apresentava resíduo vegetal de $5 \mathrm{~cm}$. A cada época, o capimAnnoni 2 foi cortado e enleirado ao sol por 5-6 horas e, após, enfardado em fardos de 6-7 kg. Os fardos de feno referentes a cada época de corte, escolhidos aleatoriamente, foram tratados (T) ou não (NT) com $4 \%$ de uréia, em base de matéria seca. Os fenos tratados, de cada época de corte, sofreram um processo de amonização, por meio da hidrólise da uréia (difusão gasosa de $\mathrm{NH}_{3}$ ) colocada em valas sob estrados contendo os fardos de feno, conforme descrição de Freitas (1992), porém sem o uso de fonte de urease, uma vez que, conforme Brown \& Adjei (1995), tal prática somente reduz o tempo de tratamento do material, sem nenhuma vantagem adicional. $\mathrm{O}$ feno, que neste método de amonização não é molhado, apresentava, em média, $10 \%$ de umidade, quando submetido ao processo de amonização.

Após 60 dias de vedação, foram coletadas amos-

R. Bras. Zootec., v.31, n.2, p.842-851, 2002 (suplemento) 
tras dos fenos tratados e dos fenos não tratados correspondentes, que se encontravam armazenados em galpão, e submetidas à análise laboratorial. Para os dois grupos de feno foi utilizada a mesma sistemática de coleta de amostra, procurando-se abranger todo o fardo de feno (exterior e interior).

Foram determinados os teores de proteína bruta (PB) pelo método de Kjeldahl, por meio da determinação do nitrogênio total (AOAC, 1975). Os componentes da parede celular: fibra detergente neutro (FDN), fibra detergente ácido (FDA), hemicelulose (HEM), celulose (CEL) e lignina (LIG) foram determinados de acordo com métodos descritos por Silva (1990). A digestibilidade in vitro da matéria orgânica (DIVMO) foi determinada utilizando-se o método proposto por Tilley \& Terry, conforme descrição de Close \& Menke (1986).

A análise estatística constou de análise de variação, teste de comparação de médias e regressão polinomial simples, quando pertinente, calculadas pelo Sistema de Análises Estatísticas para Microcomputadores SANEST (Zonta \& Machado, 1984).

\section{Resultados e Discussão}

A comparação estocástica dos dois grupos de fenos demonstrou que a amonização com $4 \%$ de uréia, em base de matéria seca, propiciou mudanças, embora nem sempre homogêneas, na maioria dos parâmetros estudados, como pode ser deduzido da Tabela 1, na qual é apresentado o resumo da análise de variação.

Enquanto para o fator tratamento dos fenos foram observadas diferenças significantes para a maioria dos parâmetros estudados, para o fator épocas de corte observou-se efeito significante somente para a PB, a FDA e a CEL. Não houve interação dos fatores para nenhum dos parâmetros estudados.

A avaliação dos teores de PB acusou uma variação altamente significante $(\mathrm{P}<0,01)$ para os fatores tratamento dos fenos e épocas de corte, sem que houvesse interação desses fatores (Tabela 1).

Os teores de PB do feno de capim-Annoni 2 decresceram com o avanço da época de corte nos dois tratamentos a que foi submetido. Entretanto, enquanto os teores do feno não tratado decresceram linear e continuamente (Figura 1), dos 30 (8,28\%) aos $150(5,53 \%)$ dias, aqueles do feno tratado apresentaram efeito quadrático, em virtude de se manterem estáveis até os 90 dias de crescimento $(\mathrm{x}=8,73 \% ; \pm 0,15)$.

A mesma tendência de queda de PB do feno de capim-Annoni 2 não amonizado foi observada por Nascimento (1976), que determinou valores da ordem de $7,06 \%$ a 2,28\% de PB, dos 30 aos 150 dias de crescimento.

No feno amonizado, em comparação com o feno não tratado, detectou-se aumento dos teores de $\mathrm{PB}$, embora não homogêneo, nas cinco épocas de corte.

Tabela 1 - Resumo da análise de variação dos teores de proteína bruta (PB), fibra detergente neutro (FDN), hemicelulose (HEM), fibra detergente ácido (FDA), celulose (CEL) e lignina (LIG) e coeficiente digestibilidade in vitro da matéria orgânica (DIVMO) do feno de capim-Annoni 2 (Eragrostis plana Nees), tratado ou não com uréia

Table 1 - Summary of the analysis of variance for crude protein (CP), neutral detergent fiber (NDF), hemicellulose (HEM), acid detergent fiber (ADF), cellulose (CEL) and lignin (LIG) levels and in vitro organic matter digestibility (IVOMD) coefficient of the Annonigrass 2 (Eragrostis plana Nees) hay treated or not with urea-ammonia

\begin{tabular}{|c|c|c|c|c|c|c|c|c|}
\hline \multirow[t]{3}{*}{$\begin{array}{l}\text { Fonte de variação } \\
\text { Source of variation }\end{array}$} & \multicolumn{8}{|c|}{$\begin{array}{l}\text { Quadrado médio } \\
\text { Mean square }\end{array}$} \\
\hline & G & PB & FDN & HEM & FDA & CEL & LIG & DIVMO \\
\hline & $D F$ & $C P$ & $N D F$ & $H E M$ & $A D F$ & $C E L$ & $L I G$ & IVOMD \\
\hline Blocos & 3 & & & & & & & \\
\hline Blocks & & & & & & & & \\
\hline Épocas de corte (A) & 4 & $8,31^{* *}$ & $7,16^{\mathrm{ns}}$ & $25,79^{\mathrm{ns}}$ & $35,65^{* *}$ & $113,89^{* *}$ & $0,87^{\mathrm{ns}}$ & $135,06^{\mathrm{ns}}$ \\
\hline Cutting ages & & & & & & & & \\
\hline Tratamento dos fenos (B) & 1 & $10,00^{* *}$ & $67,60^{*}$ & $656,10^{* *}$ & $308,02^{* *}$ & $30,62^{*}$ & $0,40^{\mathrm{ns}}$ & $78,40^{\mathrm{ns}}$ \\
\hline Hay treatments & & & & & & & & \\
\hline $\mathrm{A} \times \mathrm{B}$ & 4 & $1,06^{\mathrm{ns}}$ & $20,53^{\mathrm{ns}}$ & $23,54^{\mathrm{ns}}$ & $2,90^{\mathrm{ns}}$ & $4,81^{\mathrm{ns}}$ & $0,15^{\mathrm{ns}}$ & $35,34^{\mathrm{ns}}$ \\
\hline Resíduo & 27 & 1,02 & 9,22 & 11,86 & 4,05 & 6,09 & 0,57 & 58,32 \\
\hline Error & & & & & & & & \\
\hline Total & 39 & & & & & & & \\
\hline
\end{tabular}

ns não significante; *significante $(P<0,05)$; ${ }^{* *}$ significante $(P<0,01)$; GL: graus de liberdade.

ns not significant; * significant $(P<.05) ;{ }^{* \star}$ significant $(P<.01)$; DF: degree of freedom.

R. Bras. Zootec., v.31, n.2, p.842-851, 2002 (suplemento) 


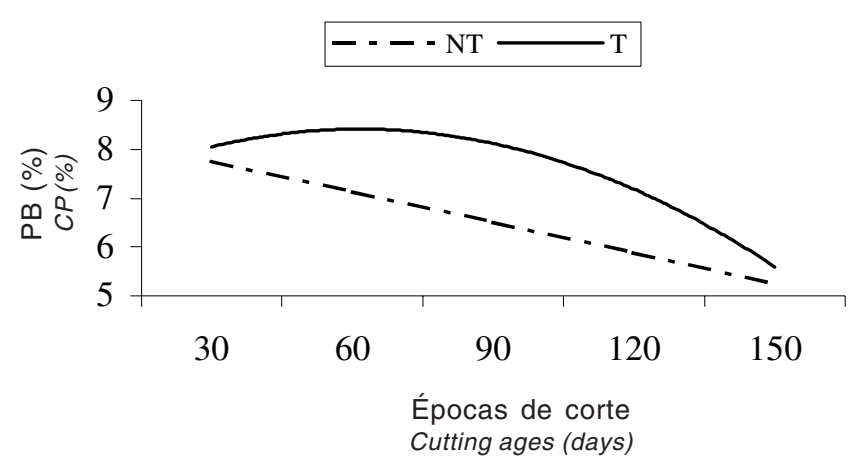

Figura 1 - Efeito do tratamento do feno de capim-Annoni 2 (Eragrostis plana Nees) com 4\% de uréia sobre os teores de proteína bruta (PB), em cinco épocas de corte (NT= não tratado; $\mathrm{T}=$ tratado).

Figure 1 - Effect of the treatment of Annonigrass 2 (Eragrostis plana Nees) hay with $4 \%$ urea on the crude protein (CP) contents, at five cutting ages (NT=not treated; $T=$ treated).

Esse aumento deve-se a duas causas principais: a primeira, e a mais importante, foi a retenção de parte do amoníaco $\left(\mathrm{NH}_{3}\right)$, que se incorporou ao material tratado na forma de hidróxido de amônio $\left(\mathrm{NH}_{4} \mathrm{OH}\right)$; a segunda foi o efeito alcalinizante que o $\mathrm{NH}_{3}$ exerce sobre as ligações ligno-celulósicas, provocando o rompimento dessas ligações e deixando mais disponíveis compostos nitrogenados, embora em pequenas quantidades, porventura ainda presentes no material analisado (Sundst $\varnothing 1 \&$ Coxworth, 1984; Van Soest, 1994a).

Comparando os teores de PB dos dois grupos de fenos, determinou-se que a amonização propiciou incremento dos teores de PB da ordem de 0,61 ; 0,$94 ; 1,95 ; 1,36$; e $0,83 \%$ nas cinco épocas de corte, respectivamente. Os maiores teores de $\mathrm{PB}$ até o corte aos 90 dias devem-se ao fato de que, quanto mais adiantado o estádio vegetativo do material a ser amonizado e, portanto, menor a qualidade, maior será a diferença constatada entre materiais tratados ou não (Sundstøl \& Coxworth, 1984; Males, 1987); já a diminuição a partir de então deve-se ao decréscimo natural dos teores de PB que as plantas apresentam em final de ciclo vegetativo, bem como em função de que em estádio vegetativo mais avançado aumenta a dificuldade de penetração do $\mathrm{NH}_{3}$ no material amonizado (Theander \& Åman, 1984), diminuindo assim a diferença dos teores de PB entre os dois grupos.

$\mathrm{O}$ efeito alcalinizante do tratamento do feno de capim-Annoni 2 determinou mudanças também em alguns parâmetros da fração fibrosa. A análise de variação dos teores de FDN demonstrou efeito significante $(\mathrm{P}<0,05)$ para o fator tratamento dos fenos. Não houve efeito para épocas de corte, nem tampouco interação dos fatores (Tabela 1).

Os teores médios de FDN dos fenos tratados ou não, correspondentes às cinco épocas de corte, são apresentados na Tabela 2.

Enquanto os teores de FDN dos fenos tratados com uréia praticamente se mantiveram no mesmo patamar, os dos fenos não tratados foram menos homogêneos, principalmente em virtude dos teores de FDN observados no corte aos 60 dias. Entretanto, os teores de FDN dos fenos não tratados, dos cortes aos $30,90,120$ e 150 dias, não diferiram estatísticamente entre si e encontram-se nos mesmos níveis dos fenos tratados. Portanto, é muito provável que o teor de FDN do feno não tratado, aos 60 dias, não espelhe um efeito real, mesmo porque se refere ao grupo de feno não tratado. Além disso, deve-se considerar que o coeficiente de variação $(\mathrm{CV}=3,69 \%)$ para os teores de FDN dos fenos dos dois grupos foi basicamente

Tabela 2 - Efeito do tratamento do feno de capim-Annoni 2 (Eragrostis plana Nees) com 4\% de uréia sobre os teores de fibra detergente neutro (FDN), em cinco épocas de corte (NT = não tratado; $T=$ tratado)

Table 2 - Effect of the treatment of Annonigrass 2 (Eragrostis plana Nees) hay with 4\% urea on the neutral detergent fiber (NDF) contents, at five cutting ages (NT = not treated; $T=$ treated)

\begin{tabular}{lcccccc}
\hline $\begin{array}{l}\text { Tratamentos } \\
\text { Treatments }\end{array}$ & \multicolumn{5}{c}{$\begin{array}{c}\text { Épocas de corte } \\
\text { Cutting ages (days) }\end{array}$} & \multirow{2}{*}{$\begin{array}{c}\text { Média } \\
\text { Mean }\end{array}$} \\
\cline { 2 - 5 } & 30 & 60 & 90 & 120 & 150 & \\
\hline NT $(\%)$ & 83,18 & 78,62 & 81,39 & 80,25 & 84,68 & $81,62^{\mathrm{b}}$ \\
T $(\%)$ & 82,88 & 84,99 & 84,02 & 84,77 & 83,90 & $84,11^{\mathrm{a}}$ \\
\hline
\end{tabular}

Médias seguidas de letras iguais, nas colunas, não diferiram pelo teste de Duncan $(\alpha=0,05)$

Means, within a column, followed by the same letters do not differ by Duncan test $(\alpha=.05)$

\section{R. Bras. Zootec., v.31, n.2, p.842-851, 2002 (suplemento)}


baixo, demonstrando haver uma diferença média mínima $(2,5 \%)$, embora significante $(\mathrm{P}<0,05)$, entre os teores de FDN dos dois grupos de feno.

É importante salientar que, embora a diferença entre os teores de FDN dos dois grupos de fenos seja mínima, no presente estudo observaram-se teores maiores de FDN nos fenos amonizados. Esse resultado não era esperado, uma vez que normalmente espera-se que o material amonizado apresente teores mais baixos de parede celular, em função da solubilização dos seus componentes. Entretanto, resultados dessa natureza são passíveis de ocorrer e foram observados mais freqüentemente em relação à fração de FDA e seus componentes (CEL e LIG), conforme Fischer et al. (1985), podendo ocorrer com outros componentes da parede celular (Sundstøl \& Coxworth, 1984).

De fato, recentemente, Cândido et al. (1999) observaram aumento dos teores de FDN do bagaço de cana amonizado com uréia, em relação ao tratamento testemunha. Da mesma forma que no presente estudo, tal resultado não fosse esperado, embora também apresentasse diferença estatística $(\mathrm{P}<0,05)$, em termos de valores absolutos, a diferença foi considerada pequena. Os autores também atribuem a diferença significante observada entre tratamentos ao baixo coeficiente de variação notado entre os teores de FDN dos dois tratamentos.

Relativamente aos teores de HEM, observou-se alta significância $(\mathrm{P}<0,01)$ para o fator tratamento dos fenos, porém nenhuma significância para as épocas de corte ou mesmo para a interação dos fatores (Tabela 1).

$\mathrm{Na}$ Tabela 3 são apresentados os teores médios de HEM dos fenos tratados ou não, nas cinco épocas de corte.

Conforme se observa, enquanto os teores de
HEM nos fenos não tratados mantiveram-se praticamente no mesmo patamar durante as cinco épocas de corte, nos fenos amonizados houve decréscimo dos teores de HEM, embora sóbrio, até a última época de corte.

Considerando os teores médios de HEM dos dois grupos de feno, observou-se uma diferença $(7,9 \%)$ altamente significante (Tabela 3 ). Todavia, o efeito da amonização, da mesma forma que o observado para a fração de FDN, não era esperado, uma vez que a amonização deveria promover diminuição dos teores de HEM.

O efeito observado deve-se ao fato de que o teor de HEM é obtido da diferença entre as frações de FDN e FDA. Como no presente estudo a fração de FDA dos fenos amonizados decresceu significativamente (Tabela 1; Figura 2) e foram detectados teores maiores de FDN para os fenos amonizados em relação aos fenos não tratados, determinaram-se teores maiores de HEM para os fenos amonizados. Tratase, entretanto, de resultados obtidos matematicamente e, assim como no caso da fração de FDN, não refletem um verdadeiro efeito do tratamento com uréia. Portanto, considera-se que também não houve efeito da amonização sobre os teores de HEM do feno de capim-Annoni 2.

Da mesma forma que para os teores de PB, também os teores da fração de FDA apresentaram diferença altamente significante $(\mathrm{P}<0,01)$ para tratamento dos fenos e para épocas de corte. Não houve interação dos fatores (Tabela 1).

A fração de FDA comportou-se de forma inversa àquela da $\mathrm{PB}$, nos dois grupos de fenos. Independentemente do tipo de tratamento, houve um aumento crescente dos teores de FDA dos fenos de capimAnnoni 2, com o avanço do estádio de desenvolvimento das plantas, em todas as épocas de corte (Figura 2).

Contudo, quando se comparam os dois tratamen-

Tabela 3 - Efeito do tratamento do feno de capim-Annoni 2 (Eragrostis plana Nees) com 4\% de uréia sobre os teores de hemicelulose (HEM), em cinco épocas de corte (NT = não tratado; $\mathrm{T}=$ tratado)

Table 3 - Effect of the treatment of Annonigrass 2 (Eragrostis plana Nees) hay with $4 \%$ urea on the hemicellulose (HEM) contents, at five cutting ages (NT = not treated; $T=$ treated)

\begin{tabular}{lcccccc}
\hline $\begin{array}{l}\text { Tratamentos } \\
\text { Treatments }\end{array}$ & \multicolumn{5}{c}{$\begin{array}{c}\text { Épocas de corte } \\
\text { Cutting ages (days) }\end{array}$} & $\begin{array}{c}\text { Média } \\
\text { Mean }\end{array}$ \\
\cline { 2 - 6 } & 30 & 60 & 90 & 120 & 150 & \\
\hline NT $(\%)$ & 35,02 & 32,53 & 33,88 & 31,96 & 33,42 & $33,42^{\mathrm{b}}$ \\
T $(\%)$ & 42,23 & 43,68 & 41,23 & 40,42 & 38,96 & $41,30^{\mathrm{a}}$ \\
\hline
\end{tabular}

Médias seguidas de letras iguais, nas colunas, não diferiram pelo teste de Duncan $(\alpha=0,05)$.

Means, within a column, followed by the same letters do not differ by Duncan test $(\alpha=.05)$.

R. Bras. Zootec., v.31, n.2, p.842-851, 2002 (suplemento) 
tos nas cinco épocas de corte, constata-se que o efeito do tratamento com uréia sobre o feno de capim-Annoni 2 foi diferente nas cinco épocas de corte. Nos cortes aos 30, 60 e 90 dias houve um decréscimo médio dos teores de FDA da ordem de 4,6\% (DP = 0,07); já nos cortes aos 120 e 150 dias, a diferença desses teores entre fenos tratados e não tratados foi $50 \%$ maior $(6,2 \%$; DP $=0,012)$.

Infere-se, portanto, que houve decréscimo significante $(\mathrm{P}<0,01)$ dos teores de FDA nos fenos tratados, em decorrência da solubilização de parte dos componentes dessa fração. O efeito observado, deve-se ao rompimento das fortes ligações entre os componentes da fração fibrosa, em função da ação alcalinizante do $\mathrm{NH}_{3}$ (Ferreira et al., 1989). Nesse caso, ocorreu redução das ligações intermoleculares entre as moléculas de CEL e, provavelmente, também ocorreu a solubilização de parte da LIG, embora não se tenha detectado diferença estatística entre os dois grupos de feno, para esta variável.

A análise de variação dos teores de CEL mostrou efeito significante $(\mathrm{P}<0,05)$ para o fator tratamento dos fenos, mas também para o fator épocas de corte $(\mathrm{P}<0,01)$. Não houve interação dos fatores (Tabela 1).

As curvas determinadas (Figura 3) apresentam um efeito claro do decréscimo nos teores de CEL, quando o feno de capim-Annoni 2 foi tratado com uréia, sendo esse efeito menor quanto mais avançado o desenvolvimento vegetativo da gramínea.

O efeito observado deve-se ao fato de que,

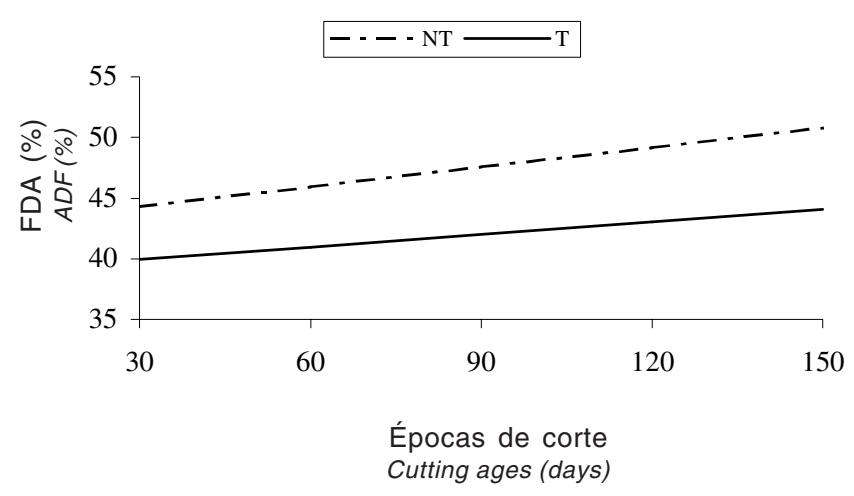

Figura 2 - Efeito do tratamento do feno de capim-Annoni 2 (Eragrostis plana Nees) com $4 \%$ de uréia sobre os teores de fibra detergente ácido (FDA), em cinco épocas de corte (NT = não tratado; $\mathrm{T}=$ tratado).

Figure 2 - Effect of the treatment of Annonigrass 2 (Eragrostis plana Nees) hay with $4 \%$ urea on the acid detergent fiber (ADF) contents, at five cutting ages $(N T=$ not treated; $T=$ treated $)$.

R. Bras. Zootec., v.31, n.2, p.842-851, 2002 (suplemento) quando materiais fibrosos são tratados com produtos alcalinos, as ligações intermoleculares - mais especificamente as pontes de hidrogênio entre as moléculas de CEL - se rompem, solubilizando esse componente da parede celular (Van Soest, 1994b). Em conseqüência, a CEL solubilizada ficou no filtrado e foram determinados teores mais baixos nos fenos tratados.

Todavia, observou-se aumento concomitante dos teores de CEL com o avanço do estádio de maturação da planta, inclusive no material tratado, demonstrando menor eficiência do tratamento com uréia, quanto mais avançado este estádio. Isso se deve ao fato de que, durante o engrossamento da parede celular, ocorre maior deposição de CEL, tanto na parede celular primária quanto na secundária (Theander \& Åman, 1984), dificultando a penetração do $\mathrm{NH}_{3}$ (Sundst $\varnothing 1$ \& Coxworth, 1984).

A avaliação dos teores de LIG não demonstrou significância para tratamento dos fenos e épocas de corte, nem tampouco houve interação dos fatores (Tabela 1).

$\mathrm{Na}$ Tabela 4 são apresentados os teores médios de LIG dos fenos de capim-Annoni 2 nos dois tratamentos, nas cinco épocas de corte.

Houve incremento dos teores médios de LIG da ordem de 1,18 pontos percentuais - com variação de $\pm 0,11$ - do primeiro ao último corte, para os dois tratamentos.

Embora não se tenha verificado diferença esta-

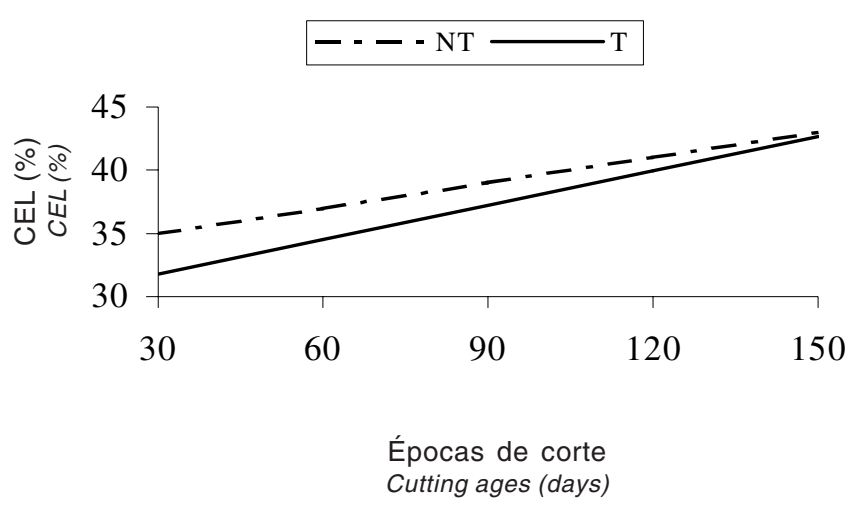

Figura 3 - Efeito do tratamento do feno de capim-Annoni 2 (Eragrostis plana Nees) com $4 \%$ de uréia sobre os teores de celulose (CEL), em cinco épocas de corte (NT = não tratado; T = tratado).

Figure 3 - Effect of the treatment of Annonigrass 2 (Eragrostis plana Nees) hay with $4 \%$ urea on the cellulose (CEL) contents, at five cutting ages (NT = not treated; $T=$ treated). 
tística entre os tratamentos, os fenos tratados com uréia apresentaram, em todos os cortes, teores médios de LIG menores que aqueles observados nos fenos não tratados, sendo, portanto, possível que parte das ligações internas das moléculas de LIG tenham sofrido ruptura (Chesson \& Orskov, 1984), solubilizando até $12 \%$ da LIG do feno tratado, em dependência da época de corte, como pode ser deduzido da Tabela 4.

No que se refere aos teores de LIG, resultados dessa natureza são passíveis de ocorrer, uma vez que a deslignificação acontece primeiramente a partir de pH acima de 8 e valores de $\mathrm{pH}$ dessa ordem são obtidos principalmente quando da utilização de álcalis fortes $(\mathrm{NaOH} ; \mathrm{KOH})$, que promovem uma deslignificação mais eficiente (Males, 1987). No caso da amonização com $\mathrm{NH}_{3}$, que é uma base mais fraca que os álcalis, ocorre menor deslignificação, sendo o tratamento menos eficiente quanto maior a fermentação dentro do silo (Van Soest, 1994c). Assim, com algumas exceções (Queiroz et al., 1992; Bonjardim et al., 1992; Rosa et al., 1998), normalmente não se observa efeito significante da amonização com $\mathrm{NH}_{3}$ sobre os teores de LIG de volumosos grosseiros.

A análise de variação dos coeficientes da DIVMO não demonstrou significância entre tratamentos, nem tampouco para as épocas de corte e interação dos fatores (Tabela 1).

Na Tabela 5 são apresentados os coeficientes médios da DIVMO dos fenos de capim-Annoni 2 nos dois tratamentos a que foram submetidos, nas cinco épocas de corte. De modo geral, os coeficientes de DIVMO foram baixos em todas as épocas de corte, nos dois tratamentos, e encontram-se abaixo dos valores médios de 49,6\% determinados por Nascimento (1976).

Apesar de não haver diferença estatística, observa-se que, com exceção do corte aos 120 dias, no qual a DIVMO foi praticamente igual nos dois tratamentos $(\neq 0,08 \%)$, nos demais cortes ela foi sempre mais baixa nos fenos tratados com uréia a, com diferenças de $-5,6 ;-3,7 ;-5,8$; e $-4,6$ pontos percentuais aos 30 , 60, 90 e 150 dias, respectivamente.

Essas diferenças, apesar de não apresentarem significância estatística, devem ser consideradas importantes em termos de digestibilidade, pois muitas vezes correspondem à melhora total ou grande parte dela, no que se refere à digestibilidade de volumosos grosseiros amonizados, em relação aos não amonizados.

Apesar de a comparação de diversos estudos encontrados na literatura ser controversa relativamente ao efeito da amonização sobre a digestibilidade dos materiais tratados - pois muitos desses não apresentam melhora deste parâmetro de qualidade (Sundstøl \& Coxworth, 1984) - no presente trabalho os coeficientes médios da DIVMO foram sempre mais baixos, justamente nos fenos tratados. É possível que o tratamento com uréia tenha afetado o inóculo negativamente.

Uma comparação dos resultados obtidos nesta pesquisa com a farta literatura sobre a amonização de volumosos grosseiros torna-se um pouco difícil em razão: 1. de que o presente estudo contemplou cinco épocas de corte e, geralmente, a amonização é feita a partir da fase de maturação das sementes; 2 . de que as características de desenvolvimento do capim-Annoni 2 diferem da maioria das outras gramíneas no que tange à fração fibrosa, uma vez que já aos 30 dias de crescimento apresenta teores acima de $80 \%$ de parede celular; 3 . de que não há estudos sobre os parâmetros de qualidade do capim-Annoni 2, principalmente no que se refere à fração fibrosa.

Entretanto, quando se considera o efeito da amonização sobre os parâmetros de qualidade de fenos e palhadas em geral, através da ação alcalinizante do $\mathrm{NH}_{3}$, observa-se que houve algumas mudanças condizentes com a expectativa, porque ocorreu aumento dos teores de PB e diminuição dos teores de FDA e CEL.

Tabela 4 - Efeito do tratamento do feno de capim-Annoni 2 (Eragrostis plana Nees) com 4\% de uréia sobre os teores de lignina (LIG), em cinco épocas de corte (NT= não tratado; T= tratado)

Table 4 - Effect of the treatment of Annonigrass 2 (Eragrostis plana Nees) hay with $4 \%$ urea on the lignin (LIG) contents, at five cutting ages (NT=not treated; $T=$ treated)

\begin{tabular}{lcccccc}
\hline $\begin{array}{l}\text { Tratamentos } \\
\text { Treatments }\end{array}$ & \multicolumn{5}{c}{$\begin{array}{c}\text { Épocas de corte } \\
\text { Cutting ages (days) }\end{array}$} & $\begin{array}{c}\text { Média } \\
\text { Mean }\end{array}$ \\
\cline { 2 - 5 } & 30 & 60 & 90 & 120 & 150 \\
\hline NT $(\%)$ & 4,49 & 4,58 & 4,65 & 5,06 & 5,78 & $4,91^{\mathrm{a}}$ \\
T $(\%)$ & 4,02 & 4,44 & 4,60 & 4,65 & 5,08 & $4,56^{\mathrm{a}}$ \\
\hline
\end{tabular}

Médias seguidas de letras iguais, nas colunas, não diferem pelo teste de Duncan $(\alpha=0,05)$.

Means, within a column, followed by the same letters do not differ by Duncan test $(\alpha=.05)$.

R. Bras. Zootec., v.31, n.2, p.842-851, 2002 (suplemento) 
Tabela 5 - Efeito do tratamento do feno de capim-Annoni 2 (Eragrostis plana Nees) com 4\% de uréia sobre os coeficientes da digestibilidade in vitro da matéria orgânica (DIVMO), em cinco épocas de corte (NT = não tratado; $\mathrm{T}=$ tratado)

Table 5 - Effect of the treatment of Annonigrass 2 (Eragrostis plana Nees) hay with $4 \%$ urea on the in vitro organic matter digestibility (IVOMD) coefficients, at five cutting ages (NT = not treated; $T=$ treated)

\begin{tabular}{|c|c|c|c|c|c|c|}
\hline \multirow[t]{2}{*}{$\begin{array}{l}\text { Tratamentos } \\
\text { Treatments }\end{array}$} & \multicolumn{5}{|c|}{$\begin{array}{l}\text { Épocas de corte } \\
\text { Cutting ages (days) }\end{array}$} & \multirow[t]{2}{*}{$\begin{array}{c}\text { Média } \\
\text { Mean }\end{array}$} \\
\hline & 30 & 60 & 90 & 120 & 150 & \\
\hline NT (\%) & 38,74 & 39,81 & 43,32 & 41,41 & 37,65 & $40,2^{\mathrm{a}}$ \\
\hline $\mathrm{T}(\%)$ & 33,15 & 36,16 & 37,57 & 41,49 & 33,04 & $36,3^{\mathrm{a}}$ \\
\hline
\end{tabular}

Médias seguidas de letras iguais, nas colunas, não diferem pelo teste de Duncan $(\alpha=0,05)$.

Means, within a column, followed by the same letters do not differ by Duncan test $(\alpha=.05)$.

Por outro lado, não foram observadas mudanças referentemente aos teores de FDN e de HEM, apesar de muitos estudos sobre a amonização apontarem para a solubilização da HEM e, com isto, para o decréscimo da fração de FDN, como uma das principais modificações que ocorrem em volumosos grosseiros, independentemente da fonte de $\mathrm{NH}_{3}$ (Bonjardim et al., 1992; Fischer et al., 1996; Rosa et al., 1998; Pires et al., 1999; Reis et al., 2001). Ao contrário, neste estudo, foram observados aumentos nos teores de FDN, mas principalmente nos teores de HEM.

Quanto à fração de FDN, o efeito observado é passível de ocorrer (Sundstøl \& Coxworth, 1984; Cândido et al., 1999). Já no que tange ao forte aumento dos teores de HEM no feno amonizado embora sendo um resultado não esperado - pode ocorrer em função de que a subtração da fração FDA da de FDN tende a superestimar os teores de HEM em gramíneas, quando são comparados aos resultados obtidos da análise individual dos açúcares que compõem a fração de HEM (Theander \& Westerlund, 1993). Também o fato de que, no presente estudo, a fração de FDN dos fenos amonizados aumentou, ao mesmo tempo que a de FDA diminuiu, justifica o efeito observado. Portanto, considerou-se que não houve efeito da amonização sobre os teores de FDN e HEM da fração fibrosa, uma vez que outros estudos com volumosos grosseiros (Queiroz et al., 1992; Reis et al., 1997; Neiva et al., 1998) também não demonstraram haver diferença desses parâmetros entre os materiais amonizados ou não.

Também não foi observado efeito da amonização sobre os teores de LIG e, provavelmente, em função disso não houve diferença significativa entre os coeficientes da DIVMO. Tais resultados merecem especial consideração, uma vez que o aumento dos teores de PB e a queda dos teores de FDA e CEL, bem como os baixos teores de LIG do feno amonizado deveriam induzir a um aumento da digestibilidade. Entretanto, no caso do capim-Annoni 2, a baixa digestibilidade dos fenos, tratados ou não, deve-se aos altos teores de FDN (Mertens, 1992) constatados já na fase inicial de crescimento da planta.

De fato, Grotheer et al. (1985) delegam a melhora na digestibilidade de materiais amonizados, principalmente à diminuição dos teores de HEM, uma vez que a digestão da HEM - cujo caráter difere nas várias espécies de plantas e tipos de parede celular - é bastante complexa em virtude de ser muito variável referentemente à composição de açúcares e ligações glicosídicas (Van Soest, 1994b).

Assim, enquanto a amonização de volumosos propicia normalmente o aumento dos teores de $\mathrm{PB}$ e, freqüentemente, a melhora do coeficiente de digestibilidade no que se refere às frações da parede celular, os estudos existentes apresentam resultados muito variados e controversos, em dependência do tipo do material amonizado, mas também da fonte de $\mathrm{NH}_{3}$. Nesse sentido, Grossi et al. (1993), utilizando distintos volumosos (feno de capim-coastcross, casca de arroz, palha de triticale, aveia) e duas fontes de $\mathrm{NH}_{3}$ (amônia anidra, uréia), obtiveram resultados distintos, de acordo com o material amonizado e com a fonte de $\mathrm{NH}_{3}$ usada. Os autores determinaram que se, por um lado, o tratamento com uréia propiciou decréscimo dos teores de FDN, CEL e LIG da casca de arroz, o mais grosseiro dos quatro volumosos utilizados, por outro lado os tratamentos com uréia ou amônia anidra não proporcionaram nenhum efeito sobre os mesmos parâmetros dos outros volumosos. Mudanças nos teores de HEM, em função do tratamento com amônia anidra, foram observadas somente no feno de capim-coastcross e na palha de triticale.

Da mesma forma, Gesualdi et al. (2001), utilizando 
bagaço e ponta de cana-de-açúcar em diferentes níveis $\left(0,1,2\right.$ e $4 \%$ ) e três fontes de $\mathrm{NH}_{3}$ (amônia anidra, uréia, sulfato de amônio) obtiveram resultados muito variados, de acordo com o material amonizado e da fonte de $\mathrm{NH}_{3}$. A exemplo disso, os teores de FDN do bagaço de cana foram influenciados por todas as fontes e, na ponta de cana, somente pelo efeito do sulfato de amônio. Os teores de HEM do bagaço e da ponta de cana foram influenciados apenas pelo tratamento com uréia. A amônia anidra influenciou somente o bagaço de cana referentemente aos teores de CEL e o sulfato de amônio, somente os teores de FDA da ponta de cana.

Os resultados supracitados e outros encontrados na literatura sobre o assunto (Martins, 1992; Reis et al., 1997; Neiva et al., 1998) demonstram não haver regras fixas para os efeitos da amonização sobre os parâmetros da fração fibrosa de volumosos grosseiros mas, sim, uma tendência esperada, pois, além da espécie de planta e da fonte de $\mathrm{NH}_{3}$, conforme Sundstøl \& Coxworth (1984), outros fatores podem influenciar os resultados finais, tais como: 1. estádio de maturação da planta; 2. temperatura, tempo e forma de armazenamento; 3 . fatores aleatórios etc. Portanto, as condições experimentais determinarão se haverá ou não efeito da amonização e qual será a sua magnitude, podendo ocorrer distintos resultados para o mesmo tipo de material e fonte de $\mathrm{NH}_{3}$, em decorrência da variabilidade daqueles fatores.

Assim, com base nessas constatações, considera-se que o objetivo principal do presente estudo foi alcançado e, de acordo com os resultados obtidos nas cinco épocas de corte estudadas, tem-se que o capim-Annoni 2 pode ser fenado até os 90 dias de crescimento sem que ocorram modificações expressivas dos parâmetros de qualidade, desde que o feno seja amonizado.

\section{Conclusões}

A amonização do feno de capim-Annoni 2 não afetou os teores de FDN, HEM e de LIG, bem como os coeficientes da DIVMO.

O tratamento do feno de capim-Annoni 2 com $4 \%$ de uréia propiciou aumento nos teores de PB e decréscimo nos teores de FDA e CEL.

O capim-Annoni 2 pode ser fenado até os 90 dias de crescimento, sem que ocorram modificações expressivas dos parâmetros de qualidade, desde que o feno seja amonizado.

R. Bras. Zootec., v.31, n.2, p.842-851, 2002 (suplemento)

\section{Literatura Citada}

ALFAYA, H.; SUÑE, L.N.P.; SILVA, D.J.S. et al. Capim-Annoni 2 (Eragrostis plana Nees). Crescimento, produção de feno e amonização. In: REUNIÃO ANUAL DA SOCIEDADE BRASILEIRA DEZOOTECNIA, 37., 2000, Viçosa. Anais... Viçosa, MG: Sociedade Brasileira de Zootecnia, 2000, Forragicultura, (1 CD-ROM)

ASSOCIATION OF OFFICIAL ANALYTICAL CHEMISTS AOAC. Official methods of analysis. 12.ed. Washington, D.C., 1975. 1094p.

BONJARDIM, S.R.; REIS, R.A.; RODRIGUES, L.R.A. et al. Avaliação da qualidade dos fenos de gramíneas tropicais armazenados com diferentes níveis de umidade e tratados com amônia. Revista Brasileira de Zootecnia, v.21, n.5, p.866873, 1992.

BROWN, W.F.; ADJEJ, M.B. Urea ammoniation effects on the feeding value of gineagrass (Panicum maximum) hay. Journal of Animal Science, v.73, p.3085-3093, 1995.

CÂNDIDO, M.D.J.; NEIVA, J.N.M.; PIMENTEL, J.C.M. et al. Avaliação do valor nutritivo do bagaço de cana-de-açúcar amonizado com uréia. Revista Brasileira de Zootecnia, v.28, n.5, p.928-935, 1999.

CHESSON, A.; ØRSKOV, E.R. Microbial degradation in the digestive tract. In: SUNDST ØL, F.; OWEN, E. (Eds.) Straw and other fibrous by-products as feed. Amsterdam: Elsevier, 1984. p.305-334.

CLOSE, W.; MENKE, K.H. Selected topics in animal nutrition. Hohenheim, Germany: DSIE, 1986. 254p.

COELHO, R.W. Capim-Annoni 2, uma invasora a ser controlada: informações disponíveis In: JORNADA TÉCNICA DE BOVINOCULTURA DE CORTE, 2., 1983, Porto Alegre. Anais... Porto Alegre: EMATER-EMBRAPA-IPZFO, 1983. p.51-70.

COELHO, R.W. Diagnóstico do problema e retrospectiva da pesquisa realizada com capim annoni 2 no CNPO e CPATB. In: REUNIÃO REGIONAL DE AVALIAÇÃO DE PESQUISA COM ANNONI 2, 1993, Bagé. Anais... Bagé: EMBRAPA-CPPSUL, 1993. p.53-69. (Documentos, 7)

COELHO, R.W.; REIS, J.C.L. Efeito da rotação soja/aveia preta no controle de capim-annoni 2. In: REUNIÃO ANUAL DA SOCIEDADE BRASILEIRA DE ZOOTECNIA, 27., 1990, Campinas. Anais... Campinas: Sociedade Brasileira de Zootecnia, 1990. p.552.

FERREIRA, A.M.; GUEDES, C.V.M.; DIAS DA SILVA, A.A. Effects of urea treatment on chemical composition and in vitro digestibility of meadow hays of Northern Portugal. Animal Food Science and Technology, v.25, p.157-167, 1989.

FISCHER, R.E.; BAYLEY, P.; HARRISON, K. et al. Nutritive value of coastal bermudagrass hay as influenced by ammoniation and grain supplementation. Arkansas Farm Research, v.34, n.3, p.8, 1985.

FISCHER, V.; PRATES, E.R.; MÜHLBACH, P.R.F. et al. Efeito do tratamento a campo da palha de arroz com uréia sobre a conservação, composição química e digestibilidade. Revista Brasileira de Zootecnia, v.25, n.5, p.837-844, 1996.

FREITAS, E.A.G. Utilização da palha de arroz na alimentação de bovinos e ovinos. Revista Lavoura Arrozeira, v.45, n.400, p.3-7, 1992.

GESUALDI, A.C.L.S.; SILVA, J.F.C.; VASQUEZ, H.M. et al. Efeito da amonização sobre a composição, a retenção de nitrogênio e a conservação do bagaço e da ponta de cana-deaçúcar. Revista Brasileira de Zootecnia, v.30, n.2, p.508517,2001 
GROSSI, S.F.; REIS, R.A.; EZEQUIEL, J.M.B. et al. Tratamento de volumosos com amônia anidra ou uréia. Revista Brasileira de Zootecnia, v.22, n.4, p.651-660, 1993.

GROTHEER, M.D.; CROSS, D.L.; GRIMES, L.W. et al. Effect of moisture level and injection of ammonia on nutrient quality and preservation of coastal bermudagrass hay. Journal of Animal Science, v.61, n.6, p.1370-1377, 1985.

HALL, G.A.B.; NASCIMENTO, A. Estudos comparativos de capim-annoni 2 (Eragrostis plana Nees) e pastagens nativas de várzeas da região de Santa Maria, RS. II. Crescimento ponderal e rebrote. Pesquisa Agropecuária Brasileira, v.13, n.2, p.15-21, 1978.

MALES, J.R. Optimizing the utilization of crop residues for beef cattle. Journal of Animal Science, v.65, n.4, p.1124-1130, 1987.

MERTENS, D.R. Analysis of fiber in feed and its use in feed evaluation and ration formulation. In: PALESTRAS DO SIMPÓSIO INTERNACIONAL DE RUMINANTES, 1992, Lavras. Anais ... Lavras: Sociedade Brasileira de Zootecnia, 1992. p.1-32.

NASCIMENTO, A. Caracterização química e digestibilidade do capim Annoni 2 (eragrostis plana Nees) comparado com o pasto nativo em diferentes estádios de desenvolvimento. Santa Maria: Universidade Federal de Santa Maria, 1976. 67p. Dissertação (Mestrado em Zootecnia) - Universidade Federal de Santa Maria, 1976.

NASCIMENTO, A.; HALL, C.A.B. Estudos comparativos de capim-annoni 2 (eragrostis plana) e pastagens nativas de várzea da região de Santa Maria, Rio Grande do Sul. I. Características químico-bromatológicas. Pesquisa Agropecuária Brasileira, v.13, n.2, p.7-14, 1978.

NEIVA, J.N.M.; GARCIA, R.; VALADARES FILHO, S.C. et al. Características químicas da silagem e do rolão de milho amonizados. Revista Brasileira de Zootecnia, v.27, n.3, p.461-465, 1998.

PIRES, A.J.V.; GARCIA, R.; CECON, P.R. et al. Amonização da quirera de milho com alta umidade. Revista Brasileira de Zootecnia, v.28, n.6, p.1186-1193, 1999.

QUEIROZ, A.C.; LEMENAGER, R.P.; HENDRIX, K.S. et al. Efeito do tratamento da palha de trigo com amônia anidra sobre a proteina bruta, digestibilidade in vitro da matéria seca e os componentes da fibra, após vários tempos de amonização e períodos de aeração. Revista Brasileira de Zootecnia, v.21, n.6, p.1020-1028, 1992.

REIS, J.C.L. Capim Annoni 2: origem, morfologia, características, disseminação. In: REUNIÃO REGIONAL DE AVALIAÇÃO DE PESQUISA COM ANNONI 2, 1993, Bagé. Anais... Bagé: EMBRAPA-CPPSUL, 1993. p.5-23. (Documentos, 7)

REIS, J.C.L.; COELHO, R.W. Como enfrentar a invasão dos campos pelo capim-annoni-2. In: FEDERAÇÃO DOS CLUBES DE INTEGRAÇÃO E TROCA DE EXPERIÊNCIASCITE (Porto Alegre-RS). Pastoreio rotativo racional: a saída da pecuária. Porto Alegre: 1999. p.105-113.
REIS, R.A.; PANIZZI, R.C.; ROSA, B. et al. Efeitos da amonização sobre a ocorrência de fungos, composição química e digestibilidade in vitro de fenos de grama seda (Cynodon dactylon (L.) Pers.). Revista Brasileira de Zootecnia, v.26, n.3, p.454-460, 1997.

REIS, R.A.; RODRIGUES, L.R.A.; RESENDE, K.T. et al. Avaliação de fontes de amônia para o tratamento de fenos de gramíneas tropicais. 1. Constituintes da parede celular, poder tampão e atividade ureática. Revista Brasileira de Zootecnia, v.30, n.3, p.674-681, 2001.

ROSA, B.; REIS, R.A.; RESENDE, K.T. et al. Valor nutritivo do feno de Brachiaria decumbens Staf cv. Basilisk submetido a tratamento com amônia anidra ou uréia. Revista Brasileira de Zootecnia, v.27, n.4, p.815-822, 1998.

SILVA, D.J. Análise de alimentos: métodos químicos e biológicos. Viçosa, MG: Universidade Federal de Viçosa, 1990. 166p.

SUNDSTØL, F.; COXWORTH, E. Ammonia treatment. In: SUNDST ØL, F.; OWEN, E. (Eds.) Straw and other fibrous by-products as feed. Amsterdam: Elsevier, 1984. p.196-247.

THEANDER, O.; ÅMAN, P. Anatomical and chemical characteristics. In: SUNDST $\varnothing$ L, F, OWEN, E. (Eds.) Straw and other fibrous by-products as feed. Amsterdam: Elsevier, 1984. p.45-75.

THEANDER, O.; WESTERLUND, E. Quantitative analysis of cell wall components. In: JUNG, H.G.; BUXTON, D.R., HATFIELD, R.D. et al. (Eds.). Forage cell wall structure and digestibility. Madison: American Society of Agronomy, 1993. p.83-104.

Van SOEST, P.J. Fiber and physicochemical properties of feeds. In: Van SOEST, P.J. (Ed.). Nutritional ecology of the ruminant. 2.ed. Ithaca: Cornell University, Cornell University Press, 1994a. p.140-155.

Van SOEST, P.J. Carbohydrates. In: Van SOEST, P.J. (Ed.). Nutritional ecology of the ruminant. 2.ed. Ithaca: Cornell University, Cornell University Press, 1994b. p.156-176.

Van SOEST, P.J. Lignin. In: Van SOEST, P.J. (Ed.). Nutritional ecology of the ruminant. 2.ed. Ithaca: Cornell University, Cornell University Press, 1994c. p.177-195.

ZONTA, E.P.; MACHADO, A.D. Sistema de análise estatística para microcomputadores-SANEST. Pelotas: Universidade Federal de Pelotas, 1984. 150p. 